\title{
EQUÍVOCOS NOS ESTUDOS LATINOS
}

\author{
HAROLDO BRUNO \\ Universidade Estadual Paulista
}

Resumo: Sob a perspectiva de que o latim é uma lingua viva (do passado) e após reflexóes de caráter lingülstico que orientam o trabalho, procuram-se apresentar algumas soluçóes lingülsticas para o ensino de latim.

Palavra-chave: Ensino; llngua; fala; competência receptiva; declinaçăo.

O primeiro grande equívoco em que se incidiu no estudo da língua latina foi aceitar o preconceito de que se lidava com o morto; sob esse princípio, todo o legado da literatura latina, por exemplo, transformou-se em um imenso "terreno sacrossanto" de onde, vez por outra, se procuravam (e ainda se procuram) ressuscitar algumas idéias ou pensamentos adormecidos; talvez por isso mesmo, haja os que confundam humanismo com verdades eternas.

A prática pedagógica tradicional do latim parece ter sempre imprimido ao estudo da língua de Roma uma orientação equivocada; exaurindo-se, por si mesma, a vertente do "filologismo" que o caracterizava, o próprio estudo do latim perdeu seu significado. Não possuindo, por exemplo, a percepção de que "todo signo se define de modo relativo e não absoluto, isto é, unicamente pelo lugar que ocupa no contexto" (Hjelmslev, 1975, p. 50), a prática pedagógica tradicional do latim tem procedido, sempre regularmente, fazendo do nome um elemento com valor absoluto, já que, como considera, se deve apreendê-lo, por intermédio da memória mecânica, por si só, desligado e desvencilhado de de qualquer contexto em que possa exercer seu papel de signo lingülstico.

Voltada primordialmente à memorização, a prática pedagógica da tradição, no que tange ao estudo dos significantes nominais, fez das desinências valores naturais de sintatização; por isso, vem sempre obrigando o aprendiz a memorizar formas de nominativo, acusativo, etc., apresentando-as como itens lexicais com valor sintático absoluto, por serem portadores de determinada desinência; dal, a insistência dessa prática com os paradigmas. Para ela, saber latim é conhecer pradigmas.

Memorizados, os conjuntos de itens lexicais com valores absolutos são levados a enunciados: o item lexical, apreendido arbitrariamente (nominativo, acusativo, etc.), passa a ser relativizado; torna-se repentinamente um significante ao ser lançado em um enunciado, entre itens lexicais necessariamente portadores de um significado; de um significado que não se realiza em latim, mas em vernáculo. Tal procedimento produz um efeito didático-pedagógico perverso: a grande dificuldade de expressar-se em português o significado de significantes latinos gera, nos que tentam estudar latim, um sentimento profundo de aversão.

Em suma, não atentando para a função semiótica do signo lingülstico, não percebendo a solidariedade que essa mesma função representa (Hjelmslev, 1975, p. 54), não reconhecendo, ou não se interessando por fazê-lo, a indissociabilidade entre significante e significado, ou por mero artiffcio assentado sobre base mnemônica, ou por simples comodidade didática, a prática pedagógica tradicional elege o estudo paradigmático do significante dessintagmatizado; anatomiza, assim, o léxico nominal segundo o falso pressuposto da compatibilidade morfológica en- 
tre um conjunto, mais ou menos restrito, denominado desinências, e um outro, amplo, denominado radical; tal procedimento explica "as cinco declinaçōes" dos substantivos e "as duas classes" de adjetivos. Desse modo, têm-se significantes, mas não significados, pois não se exige a compreensão, mas sim a memorização. Com tal estratégia propedêutica, ao aprendiz somente se podem oferecer frases que se organizam em abracadabras, porque se lhe apresentam significantes cuja relação com significados é totalmente desconhecida.

Não tendo intuldo "o sentimento de valor comum", segundo o define Saussure (Saussure, 1972, p. 160-61), atribuindo, pois, ao significante um valor absoluto, por ser apreendido mnemonicamente, à parte de qualquer contexto, a prática tradicional do latim sempre deriva 0 significado não de oposiçōes entre os significantes, mas das desinências tomadas absolutamente. Basta manusear seus velhos ou novos manuais para constatar esse procedimento; encontra-se neles toda uma série de desinências (por exemplo, nom. -a, acus. -am, gen. -ae, abl. $-a$, dat. -ae, etc.) que, por si sós, sem relação alguma com qualquer outro elemento, são apresentadas como marcadas com o valor de caso. Como o aprendiz não pode memorizar todo o léxico, memoriza-as; aplicá-las é outra questāo.

A prática pedagógica tradicional do latim transformou-o de sua condição de língua, enquanto sistema, em um código cifrado. O aprendiz converte-se, assim, em desventuroso criptonalista, já que, não tendo sido capacitado para comportar-se perante o texto latino como um receptor de uma mensagem, isto é, năo possuindo a possibilidade de, por meio do código lingülstico, compreender uma mensagem, transforma-se em um decifrador.

Segundo o que pensamos, o ensino do latim deve objetivar oferecer condiçōes adequadas para que quem não o possua como lingua materna (e ninguém o possui hoje!) possa ser um destinatário virtual de qualquer fala autenticamente latina: um decodificador e não um decifrador. O latim é, mesmo hoje, um instrumento cultural de comunicação, ainda que virtual e unidirecional, unindo um emissor de um passado remoto a um destinatário sempre posterior.

Uma das conseqüências equivocadas, entre tantas outras, que a transmutação da lingua latina de sistema lingüistico em código cifrado acarreta é o mito de que, em latim, a ordem das palavras não importa para o sentido; costuma-se, também, considerar essa "peculiaridade" do latim um dos componentes intensificadores da dificuldade de seu ensino-aprendizagem. Quanto a esse mito, primeiramente há que considerar-se que a organização da frase latina, é tão ou mais importante e necessária que a da língua portuguesa: de um lado, porque "lingüfsticamente, uma frase é algo diferente da soma das palavras que a formam" (Martinet, 1968, p. 220); de outro, porque a alocação das palavras na frase latina revela mais intensamente uma intenção conotativa ou mesmo uma intenção informativa diferenciadora. Referentemente à intenção conotativa ou informativa diferenciadora, o enunciado "ancillam dominus uocat" (supondo-o dito por um romano) não será igual à "dominus ancillam uocat", que é diferente de "uocat ancillam dominus", que é diverso de "uocat dominus ancillam", que é distinto de "dominus uocat ancillam", que não é o mesmo que "ancillam uocat dominus". O que ocorre é que, no plano formal da expressão, esses deslocamentos de posição são exemplificadores de variantes locativas da oposiçấo invariante nominativo (dominus)/acusativo (ancillam), sintatizada por uma forma verbal (uocat). Nessas seis possibilidades de alocação lexical, repetir-se-ão, pois, os mesmos sintagmas nominais (nominativo e acusativo), que, em todas elas, constituirão a mesma oposiçăo. Apenas quanto a isso, ou seja, somente quanto à indestrutibilidade da oposição nominativo/acusativo, é que se pode afirmar que não se leva em conta a ordem das palavras. Em outros termos, a disposição das palavras na frase latina não interfere na oposição casual, mas a cada variação de posição corresponde um novo investimento semântico no que diz respeito ao sentido conotado; não se pode esquecer de que a uma modificação no plano de expressão corresponde uma modificação no planto do conteúdo.

Esse mesmo fenômeno ocorre em português, já que as oposiçōes que em latim se instauram pelos morfemas casuais são, em nossa lingua, fundadas, de um lado (e em primeiro lugar) pela oposiçăo espacial, a que Carvalho denomina "mortema de posiçăo" (Carvalho, 1973, p. 621); de outro (e em segundo lugar), pela expressão preposicional, que, segundo Martinet, 
confere a mesma autonomia sintagmática proporcionada pela expressāo casual (Martinet, 1968 , p. 176). Do enunciado "o patrāo chama a criada", cujo sentido decorre da oposição marcada pelo "mortema de posição", poder-se-ão derivar os enunciados "à criada chama o patrão", "chama à criada o patrão, "chama o patrão à criada", "o patrão à criada cinama" e "à criada o patrão chama", cujo sentido é produzido pela expressão preposicional. Portanto, não é exato afirmar que a ordem das palavras na frase latina não interessa ao sentido; o correto é afirmar que as oposiçōes expressas pelos morfemas casuais não se desfazem sejam quais forem as posições 'que as palavras possam vir a ocupar no enunciado latino. A ordem das palavras "é um dos mais valiosos artifícios emotivos da sintaxe [...]. Isto é particularmente verdade nas línguas [...], tais como o latim, onde as palavras podem ser livremente movidas com o intuito de realce ou de efeitos emotivos" (Ullmann, 1973, p. 284).

A noção de traço distintivo, ou seja, a função distintiva dos fonemas ("a troca de um fonema por outro fonema pode provocar uma diferença de conteúdo..." - Hjelmslev, 1975, p. 67) pode ter importantes reflexos no estudo dos significantes nominais ou verbais latinos; a extensão da sua aplicação recobre os léxicos (pro-)nominal e verbal. Mas, para sua eficácia, é necessário que se tenha presente a lição de Martinet segundo a qual a uma diferença de forma corresponde necessariamente uma diferença de sentido (Martinet, 1970, p. 34). É preciso, também, não se esquecer de que, em latim, os (pro-)nomes não existem no estado que UIImann denomina "estado puro", libertos "de associações contextuais" (Ullmann, 1973, p. 83) - o que implica a remota possibilidade de um nome latino possuir significado genérico, descontextualizado, como, por exemplo, o português pedra; conforme ensina Ulimann, "em latim [...] acontece muitas vezes que uma palavra não existe em estado abstrato, como pura designação da coisa que representa; existe annus, nominativo singular, annum, acusativo singular, annorum, genitivo plural, etc. Mas não há uma única forma designando apenas a idéia de 'ano' " (1973, p. 93); a lição de Ullmann cresce em consistência se aproximada à de que "qualquer elemento lingüistico só tem realmente valor quando integrado em um contexto ou em situaçăo (Martinet, 1970, p. 35). A produtividade da função distintiva ganha relevo acentuado se não for dissociada do que Saussure denomina "sentimento de um valor comum (dos casos), que dita um emprego idêntico" (desses casos, seja qual for seu tema) (Saussure, 1972, p. 160-61) e desde que se entenda por casos um conjunto de seis constantes que, por um processo de oposiçāo e por um processo de mutatibilidade de classe lexical intrafrásticos, conferen uma identidade a si e um sentido à frase.

Definidas as constantes pelo processo mencionado, isto é, sintagmaticamente, mostrarse-ão na frase através de formas variantes que se expandem horizontalmente (ou intertematicamente), por meio das diversas configuraçōes temáticas (dai, a importância da noção de "sentimento de valor comum dos casos") e verticalmente (ou intratematicamente), através de um paradigma; depreende-se assim, mais uma vez, que qualquer mudança intraparadigmática acarretará uma diferença sintagmática. Em outras palavras, as primeiras variações horizontais, as intertemáticas, apresentam elementos distintivos tais que possibilitam a apreensão do sentimento do valor comum dos casos por meio dos morfemas, enquanto as segundas, as intratemáticas, se manifestam, não propriamente através de desinências, mas pela compatibilidade/incompatibilidade de morfemas com sıas bases temáticas, constituindo conjuntos aparentemente diferenciados que, indevidamente, foram denominados declinaçőes. Conclui-se, pois, da idêia das expansões horizontais e verticais, intermáticas e intratemáticas, que em latim existe apenas um conjunto declinatório constituldo pela invariåncia dos casos. Em suma, o sentimento de valor comum dos casos (variantes intertemáticas) liga-se a um conjunto de constantes, abstrato por sua própria essência, que se manifestam concretamente quando realizam sua função semiótica, através das variantes intratemáticas.

A prática pedagógica tradicional do latim não se preocupa com observar os processos de oposição e mutabilidade de classe lexical intrafrásticos, sintagmáticos, atentando unicamente para o paradigma enquanto forma fisica (que não é significante nem palavra) de um significado vazio, não integrado a um contexto. No artiffcio pedagógico dos paradigmas de declinaçס́es 
não há a idéia de oposição e de mutabilidade intrafrástica, intrassintagmática, pelo fato de o paradigma ser considerado uma variante intratemática em que se desfaz a função semiótica das constantes casuais, pois o "reconhecimento" deixa de operar-se por meio de seu valor relativo, através do processo de oposição e de mutabilidade intrassintagmática; quanto a isso, é preciso também não se esquecer da lição de Martinet: "não poderå considerar-se existente numa língua qualquer unidade, gramatical ou lexical, que não se oponha a outras categorias do mesmo tipo por diferenças fônicas características" (Martinet, 1970, p. 35).

Com o procedimento tradicional de declinarem-se palavras, o aprendiz é levado, por meio da estratégia, dos paradigmas, a operar apenas com modificações, sem que elas impliquem necessariamente uma diferença correspondente de sentido. Observando-se, em manuais ou dicionários, os paradigmas nominais latinos, ou melhor, a distribuição "hierárquica" das constantes casos, verifica-se que a forma da constante nominativo é a primeira, a do genitivo, a segunda, etc.; por que essa hierarquização e não outra? O elemento agregador das variantes intratemáticas é, obviamente, o tema: a hierarquia ou a disposição ordenada de suas variações é um "ato puramente arbitrário" (Saussure, 1972, p. 147).

Se o latim foi extinto do curso médio e teve sua carga horária reduzida nos cursos de Letras, não se pode afirmar que "tenha sido derrubado por causa de sua pouca utilidade", ou mesmo, em virtude de "sua total inutilidade"; o latim "caiu" também em virtude de uma sua prática pedagógica catequética. $O$ ensino que não é lingüístico, que não supõe uma fundamentação científica, não só quando aos procedimentos utilizados para a investigação, mas principalmente quanto ao embasamento do conteúdo transmissivel, o que lhe dará sustentação dialética e o estatuto de saber, procura artificios e estratagemas para poder impor-se; envelhecendo, perde a razão de ser como "informação" a ser transmitida; desagasta-se e desaparece. Justifica-se o paradigma-declinação se, por suas variaçōes, se associar às constantes que semiotiza. O processo semiótico dá-se substancialmente no sintagma, em virtude da relação necessária entre significante e significado e segundo o princlpio de que qualquer modificação na expressão corresponde a uma conseqüente modificação de conteúdo, como já se viu mais acima; assim, "uma declinação não é nem uma lista de formas, nem uma série de abstrações Iógicas, mas uma combinação dessas duas coisas: formas e funçōes são solidárias e é diffcil, para não dizer impossivel, separá-las" (Saussure, 1972, p. 157).

Com vistas à aquisição de produtividade lingülstica, as variações intratemáticas deverão sempre relacionar-se intertermaticamente, fato que lhes assegurará, de um lado, a condição de paradigma no que se refere às modificaçōes fônicas, próprias de cada tema e, de outro, o sentimento de valor comum, regulador de seu uso no que tange à função semiótica.

Considerando as variaçōes intratemáticas e intertemáticas não como processos de concretização semiótica de um conjunto de constantes da declinação latina, mas como constituintes de cinco processos de diferentes declinaçōes, a prática pedagógica tradicional do latim induz a equivocos mesmo renomados lingülstas. Em uma remissão à face dupla de um monema - significante e significado -, Martinet adverte que pode ocorrer que "dois significados coexistentes no enunciado combinem de tal maneira seus significantes, que o produto de tal combinação não seja analisável em segmentos sucessivos" (Martinet, 1970, p. 104); como exemplo da impossibilidade de segmentação de monemas desse tipo, que denomina amalgamados, cita o mesmo autor a forma do genitivo malorum, "das maçãs (ou das macieiras, ou dos maus, ou dos males)" em que "-orum" serve de significante aos dois significados "genitivo" e "plural", sem que possamos precisar o que corresponde a um e a outro" (ibid.). O equivoco de Martinet consiste em apresentar, segundo a prática pedagógica tradicional do latim, a forma -orum como "desinência" do genitivo plural; cotejando-se, contudo, a forma malorum com rosarum e com rerum, todas formas de genitivo plural, ver-se-á que o elemento comum a elas é -um, proveniente de um antigo "-som, este sim o monema amalgamado do genitivo plural. O que possibilita a esses itens lexicais apresentarem a mesma forma de morfema é terem em comum um tema vocálico, malo-, rosa- e -re, como o qual é compativel o morfema de genitivo plural "-rum". Não se trata, pois, de três desinências (-orum, -arum e -erum), mas estratagema de uma prática 
pedagógica que visa à retençăo mecânica, que não contempla, naquilo que interessa à lingüistica como pesquisa e como pedagogia, a variação intertemática de um morfema.

Para demonstrar que, no latim, "a palavra se confunde geralmente com a unidade acentual e os significantes dos monemas que compóem aquela se enredam por vezes de modo inextricável", ainda o mesmo Martinet, servindo-se de dominus, procura examinar os monemas de significado "senhor", "nominativo" e "singular". Quanto ao monema de "significado", após considerar domin- um radical do latim clássico, que significa "senhor" apenas em combinação com uma série de desinências", classifica -us como o monema do "nominativo" e do "singular", desde que associado ao radical domin-; conclui, então, que se vê "claramente que a análise dos significantes distintos só poderia complicar (...) a exposição, sem trazer vantagens consideráveis. Por isso é largamente preferivel recorrer, no caso do latim, ao método tradicional de expor os fatos, considerando dominus uma palavra da segunda declinação" (Martinet, 1970, p. 117-18).

Considerar, segundo a prática pedagógica tradicional do latim, dominus um nome da segunda declinação falseia uma solução, por ser subterfúgio. Em primeiro lugar, porque dominus não significa "senhor", "nominativo" e "singular"; dominus significa "senhor", enquanto for sujeito de enunciado; aí será "nominativo" e "singular", enquanto "senhor" the for um seu correspondente em um enunciado português; em segundo lugar, no que se refere ao léxico em geral, é, sob a perspectiva do ensino lingüistico, contraproducente operar com radicais: ao mesmo tempo que domin- é radical de uma das realizações sintagmáticas de "senhor" (dominus...), é também uma das de "senhora" (domina...). Como já se viu anteriormente, não existe, em latim, uma forma monemática plena que tenha o significado genérico, como, por exemplo, de "senhor"; esse significado descontextualizado, isto é, isolado de qualquer situaçăo frástica, poderia ser fornecido pelo tema domino-, inexistente em "estado puro", mas que se manifesta em toda a variação intratemática; por isso, apenas segundo a prática tradicional de expor os fatos gramaticais é que -us é desinência do nominativo singular; na verdade, o monema do "nominativo" e do "singular" é apenas -s.

Para um tratamento lingüistico do latim, não se pode conceber a idéia da existência de declinaçōes, mesmo que, para explicar a existência de um conjunto de constantes demoninadas casos e suas formas de realização, seja necessário recorrer a noçōes rudimentares da diacronia (fonetismo).

É preciso convencer-se de que, quando se trabalha com o latim, se está trabalhando com uma fala, com uma língua vivente; ou, para fugir a um termo que remete a uma categoria dos reinos animal e vegetal, está-se diante de uma língua-em-função. Não aceitar o princípio da existência da língua-em-funçăo significa recusar um Dicionário de Usos, sob o argumento de que nele não se registra o uso, mas o usado.

\section{Resumé:}

Ayant em vue que le latin est une langue vivante (du passé) e aprés la mise au point de quelques reflexions linguistiques qui sont à la base du travail, on tâche de présenter quelques unes solutions linguistiques pour l'enseignement de la langue de Rome. On cherche à eviter des équivoques de la vielle pédagogie humaniste. 


\section{REFERÊNCIAS BIBLIOGRÁFICAS}

CARVALHO, J. G. H. Teoria da Linguagem. Natureza do fenômeno lingülstico e a análise das linguas. Coimbra: Atlântida, 1973.

HJELMSLEV, L. Prolegômenos a uma Teoria da Linguagem. São Paulo: Perspectiva, 1975.

JAKOBSON, R. Lingüística e Comunicação. São Paulo: Cultrix, 1971.

MARTINET, A. La Lingüística Sincronica. Estudios e Investiciones. Madrid, Gredos, 1968.

MARTINET, A. Elementos de Lingüistica Geral. Lisboa: Sá da Costa, 1970.

SAUSSURE, F. de. Curso de Lingülstica Geral. São Paulo: Cultrix, 1972.

ULLMANN, S. Semântica. Uma introdução à Ciência do Significado. Lisboa, Gulbenkian, 1973. 